\title{
Arbuscular mycorrhizal fungi are an alternative to the application of chemical fertilizer in the production of the medicinal and aromatic plant Coriandrum sativum L.
}

\author{
Rui S. Oliveira ${ }^{\mathrm{a}, \mathrm{b}, \mathrm{c}}$, Ying Ma ${ }^{\mathrm{a}}$, Inês Rochaa, Maria F. Carvalho ${ }^{\mathrm{d}}$, Miroslav Vosátka ${ }^{\mathrm{e}}$, and Helena Freitas ${ }^{\mathrm{a}}$
}

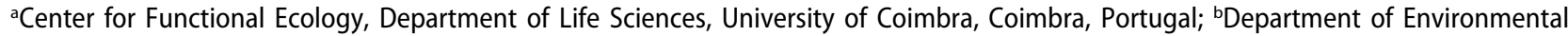
Health, Research Centre on Health and Environment, School of Allied Health Sciences, Polytechnic Institute of Porto, Vila Nova de Gaia, Portugal; 'CBQF-Centro de Biotecnologia e Química Fina-Laboratório Associado, Escola Superior de Biotecnologia, Universidade Católica Portuguesa, Porto, Portugal; 'CIIMAR-Interdisciplinary Center of Marine and Environmental Research, University of Porto, Porto, Portugal; eInstitute of Botany, Academy of Sciences of the Czech Republic, Průhonice, Czech Republic
\end{abstract}

\begin{abstract}
The widespread use of agrochemicals is detrimental to the environment and may exert harmful effects on human health. The consumer demand for organic food plants has been increasing. There is thus a rising need for alternatives to agrochemicals that can foster sustainable plant production. The aim of this study was to evaluate the potential use of an arbuscular mycorrhizal (AM) fungus as an alternative to application of chemical fertilizer for improving growth performance of the medicinal and aromatic plant Coriandrum sativum. Plants were inoculated with the AM fungus Rhizophagus irregularis BEG163 and/or supplemented with a commercial chemical fertilizer (Plant Marvel, Nutriculture Bent Special) in agricultural soil. Plant growth, nutrition, and development of AM fungus were assessed. Plants inoculated with $R$. irregularis and those supplemented with chemical fertilizer displayed significantly improved growth performances when compared with controls. There were no significant differences in total fresh weight between plants inoculated with $R$. irregularis or those supplemented with chemical fertilizer. Leaf chlorophyll $a+b(82 \%)$, shoot nitrogen $(44 \%)$, phosphorus (254\%), and potassium (27\%) concentrations increased in plants inoculated with $R$. irregularis compared to controls. Application of chemical fertilizer inhibited root mycorrhizal colonization and the length of the extraradical mycelium of $R$. irregularis. Inoculation with $R$. irregularis was equally or more efficient than application of chemical fertilizer in promoting growth and nutrition of $C$. sativum. AM fungi may thus contribute to improve biologically based production of food plants and reduce the dependence on agrochemicals in agriculture.
\end{abstract}

The application of chemical fertilizers and pesticides is a major source of environmental pollution (Turra et al., 2010). Agrochemicals might lead to reduced ecosystem functioning, as well as soil and water degradation (Power, 2010). Agrochemicals might also exert deleterious effects on human health, particularly through exposure of workers in the agroecosystem (Meyer et al., 2010; Alavanja and Bonner, 2012; Freire et al., 2015) or the intake of contaminated food crops (Carvalho, 2006). Currently, the market share for ecologically produced crops is constantly increasing due to customer demands for safer and healthier food (Lim et al., 2014). Another emerging driving force for enhancement of more biologically based cultivation of agricultural crops is the continuous attempts within European Union regulations to reduce inputs of agrochemicals (European Commission, 2007; Skevas et al., 2013). There is thus a rising need to find alternatives instead of application of chemical fertilizers in plant production.

Arbuscular mycorrhizal (AM) fungi are a group of soil microorganisms that form a symbiotic association with plants (Oliveira et al., 2001). AM fungi colonize plant roots and produce hyphae that penetrate into the soil and create a network of extraradical mycelium (ERM). The ERM links colonized roots with the soil matrix and translocates nutrients from soil to roots (Oliveira et al., 2010). Therefore, AM fungi have the capacity to promote plant growth by 
improving the uptake of nutrients, such as nitrogen $(\mathrm{N})$, phosphorus $(\mathrm{P})$, potassium $(\mathrm{K})$, calcium $(\mathrm{Ca})$, sulfur $(\mathrm{S})$, copper $(\mathrm{Cu})$, and zinc $(\mathrm{Zn})$, among others (Oliveira et al., 2005a, 2006; Willis et al., 2013). Studies showed that plants inoculated with AM fungi display not only improved growth, but also superior food quality properties, such as increased content of antioxidants, vitamins, and minerals (Albrechtová et al., 2012; Baslam et al., 2013). This AM fungi-mediated added value for food plants contributes to food quality and provides benefits to human health. In addition to their role in plant nutrition, AM fungi possess several other beneficial effects on plants, including improvement of drought tolerance (Augé et al., 2015) and protection against soil-borne plant pathogens (Sikes et al., 2009). Therefore, the potential use of AM fungi may improve biologically based production of food plants.

Coriandrum sativum L., Apiaceae (coriander), is a medicinal and aromatic plant species native to the Mediterranean region. Coriandrum sativum is cultivated globally due to its use in culinary practices and cosmetics (Maroufi et al., 2010). The leaves and the essential oil of the seeds of this economically important herb possess several pharmacological activities, such as antioxidant, antihyperglycemic, anxiolytic, diuretic, anti-inflammatory, antibacterial, antifungal, and anthelminthic (Mahendra and Bisht, 2011; Sahib et al., 2012). Coriandrum sativum is known to form symbiotic associations with AM fungi (Schroeder and Janos, 2004). However, few data are available on the outcomes of symbiosis for both plant and fungi in plant production systems.

The aims of the present investigation were to (i) determine the effect of AM fungal inoculation on growth and nutrition of $C$. sativum and (ii) assess whether AM fungi may serve as a feasible alternative rather than application of chemical fertilizer (Plant Marvel, Nuticulture Bent Special, PMNBS) for sustainable production of food plants.

\section{Materials and methods}

\section{Experimental design and setup}

The two mericarps of $C$. sativum seeds were manually separated and surface sterilized with $0.5 \%(\mathrm{v} / \mathrm{v})$ sodium hypochlorite for $10 \mathrm{~min}$, placed between moist paper towels, and germinated at $20^{\circ} \mathrm{C}$ in the dark. After germination, seedlings of similar size were transplanted singly into $1-\mathrm{dm}^{3}$ pots containing agricultural soil. The soil was collected from the uppermost $10-\mathrm{cm}$ layer of an organic farm in northern Portugal, sieved through a 4-mm mesh, and autoclaved twice $\left(121^{\circ} \mathrm{C}\right.$ for $\left.25 \mathrm{~min}\right)$ on two consecutive days. The soil was a sandy loam with $\mathrm{pH}$ (1:2.5 w/v water) 6.3 , electrical conductivity 0.14 $\mathrm{dS} / \mathrm{m}, 3.3 \%$ organic matter, $0.24 \%$ total $\mathrm{N}, 51.5$ $\mathrm{mg} / \mathrm{kg}$ extractable (Egner-Riehm) P, $8.7 \mathrm{~g} / \mathrm{kg} \mathrm{K}, 2$ $\mathrm{g} / \mathrm{kg} \mathrm{Ca}, 137 \mathrm{mg} / \mathrm{kg}$ magnesium (Mg), and $452 \mathrm{mg} /$ $\mathrm{kg}$ sodium $(\mathrm{Na})$. Microbial populations from the original nonsterile soil were reintroduced to each pot by adding $10 \mathrm{ml}$ of filtrate as described in Oliveira et al. (2005a). A nitrocellulose membrane filter $(24 \mathrm{~mm}$ diameter and $0.4 \mu \mathrm{m}$ pore size; Pragopore, Pragochema Ltd., Czech Republic) was inserted vertically in each pot for future measurements of ERM length (Baláz and Vosátka, 2001). The experiment comprised 4 treatments: (i) control, (ii) plants supplemented with a commercial chemical fertilizer (PMNBS) (iii) plants inoculated with an AM fungus, and (iv) plants supplemented with PMNBS and inoculated with an AM fungus. All treatments were replicated 10 times. The AM fungal isolate used in this study was Rhizophagus irregularis BEG163. It was grown for $8 \mathrm{mo}$ in a multispore pot culture containing a $1: 1(\mathrm{v} / \mathrm{v})$ mixture of zeolite and sand with Trifolium pratense $\mathrm{L}$. as host plant. At transplanting, each pot from the mycorrhizal treatments received $10 \mathrm{~g}$ inoculum consisting of colonized root fragments, hyphae, and spores in the mixture of zeolite and sand, placed $2 \mathrm{~cm}$ below the root system. Every pot from the nonmycorrhizal treatments received $10 \mathrm{~g}$ inoculum autoclaved twice $\left(121^{\circ} \mathrm{C}\right.$ for $\left.25 \mathrm{~min}\right)$ on consecutive days. In order to eliminate differences in microbial populations introduced with the AM fungal inoculum, $5 \mathrm{ml}$ of a suspension of AM fungal inoculum was added to each pot from the nonmycorrhizal treatments (Koide and Li, 1989). The suspension was prepared as described in Oliveira et al. (2010). Plants supplemented with chemical fertilizer received $25 \mathrm{ml}$ of a commercial chemical fertilizer $\left(200 \mathrm{mg} / \mathrm{L} \mathrm{N}, 57 \mathrm{mg} / \mathrm{L} \mathrm{P}_{2} \mathrm{O}_{5}, 130 \mathrm{mg} / \mathrm{L} \mathrm{K}_{2} \mathrm{O}\right.$, $0.5 \mathrm{mg} / \mathrm{L} \mathrm{S}, 0.4 \mathrm{mg} / \mathrm{L} \mathrm{Mg}, 0.4 \mathrm{mg} / \mathrm{L} \mathrm{Cu}, 0.4 \mathrm{mg} / \mathrm{L} \mathrm{Zn}$, $0.4 \mathrm{mg} / \mathrm{L} \mathrm{Mn}, 1.4 \mathrm{mg} / \mathrm{L} \mathrm{B}, 0.7 \mathrm{mg} / \mathrm{L} \mathrm{Fe}, 0.007 \mathrm{mg} / \mathrm{L}$ 
Mo) per pot 3 times per week. Nonfertilized plants received $25 \mathrm{ml}$ deionized water. Plants were grown in a greenhouse under an average photoperiod of 12 h. Temperature and relative humidity ranges were $15-40{ }^{\circ} \mathrm{C}$ and $60-80 \%$, respectively. Pots of different treatments were periodically rotated to different bench positions to minimize differences due to their location in the greenhouse.

\section{Plant parameters analyses}

After a growth period of $62 \mathrm{~d}$, plants were removed from the pots. The root system was separated from the shoot and washed to remove adhered soil. Root and shoot were weighed and the sum of their masses yielded the total plant fresh weight. The root/shoot fresh weight ratio was calculated by dividing the root by shoot mass. A fresh subsample $(0.02 \mathrm{~g})$ was cut from the second mature leaf from the plant apex and the concentrations of chlorophyll a, chlorophyll $b$, and chlorophyll $a+b$ determined after extraction with $\mathrm{N}, \mathrm{N}$-dimethylformamide according to Wellburn (1994). Shoots were dried at $70^{\circ} \mathrm{C}$ for $48 \mathrm{~h}$ and $0.3 \mathrm{~g}$ of finely ground material was digested as described in Novozamsky et al. (1983). Phosphorus and $\mathrm{N}$ concentrations in shoots were determined by colorimetry (Spectronic Genesys 10 Bio, Thermo Electron Corporation, USA), while $\mathrm{K}$ concentration was determined by flame atomic emission spectroscopy (Walinga et al., 1989).

\section{Fungal parameters analyses}

A subsample $(0.2 \mathrm{~g})$ of fresh roots of C. sativum was cut into $1-\mathrm{cm}$ pieces and stained with trypan blue using a modified Phillips and Hayman (1970) protocol (Oliveira et al., 2005b). Percentage root length colonized (RLC) by AM fungi was assessed using the grid-line intersect method (Giovannetti and Mosse, 1980) under a stereomicroscope (Olympus SZ61, Japan). Stained root pieces were mounted on glass slides and examined with a compound microscope (Leica DM 750, Germany) $(\times 100-400)$ to assess abundance of arbuscules in the mycorrhizal root segments (Trouvelot et al., 1986). Arbuscule abundance was determined using the software Mycocalc (http://www.dijon.inra.fr/ mychintec/Mycocalc-prg/download.html) and expressed as percent of the colonized root length occupied by arbuscules. ERM length was determined by the inserted membrane technique (Baláz and Vosátka, 2001) followed by the gridline intersect method under a compound microscope (Leica DM 750, Germany), using an ocular grid at $\times 200$ magnification (Brundrett et al., 1994). Background lengths of mycelium found in nonmycorrhizal treatments were subtracted from the values obtained in the corresponding mycorrhizal treatments and the ERM length wqas expressed in centimeters of hyphae per $1 \mathrm{~cm}^{2}$ of the inserted membrane filter.

\section{Statistical analysis}

Normality and homogeneity of variances were confirmed and data analyzed using two-way analysis of variance (ANOVA) for each dependent variable (plant parameters) versus the independent variables (fungal inoculation and fertilization). When a significant $F$ value was obtained $(p<.05)$, treatment means were compared using Duncan's multiple-range test. Fungal parameters data were analyzed without including the respective noninoculated control treatments using Student's $t$-test at a significance level of $p<$ 0.05 . All statistical analyses were performed with the SPSS 20.0.0 software package (IBM SPSS Statistics, USA).

\section{Results and discussion}

\section{Plant growth}

Both the application of chemical fertilizer and inoculation with $R$. irregularis significantly improved growth of $C$. sativum compared with controls (Figure 1). There were no significant differences in total fresh weight between plants supplemented with chemical fertilizer and those inoculated with $R$. irregularis (Figure 1C). Fungal inoculation exerted the same effect on shoot fresh weight of $C$. sativum as application of chemical fertilizer (Figure 1A). The shoots including stem and leaves are among the most valuable parts of $C$. sativum for culinary, cosmetic, and medicinal uses (Maroufi et al., 2010; Sahib et al., 2012). Although AM fungi are known to increase plant biomass and 

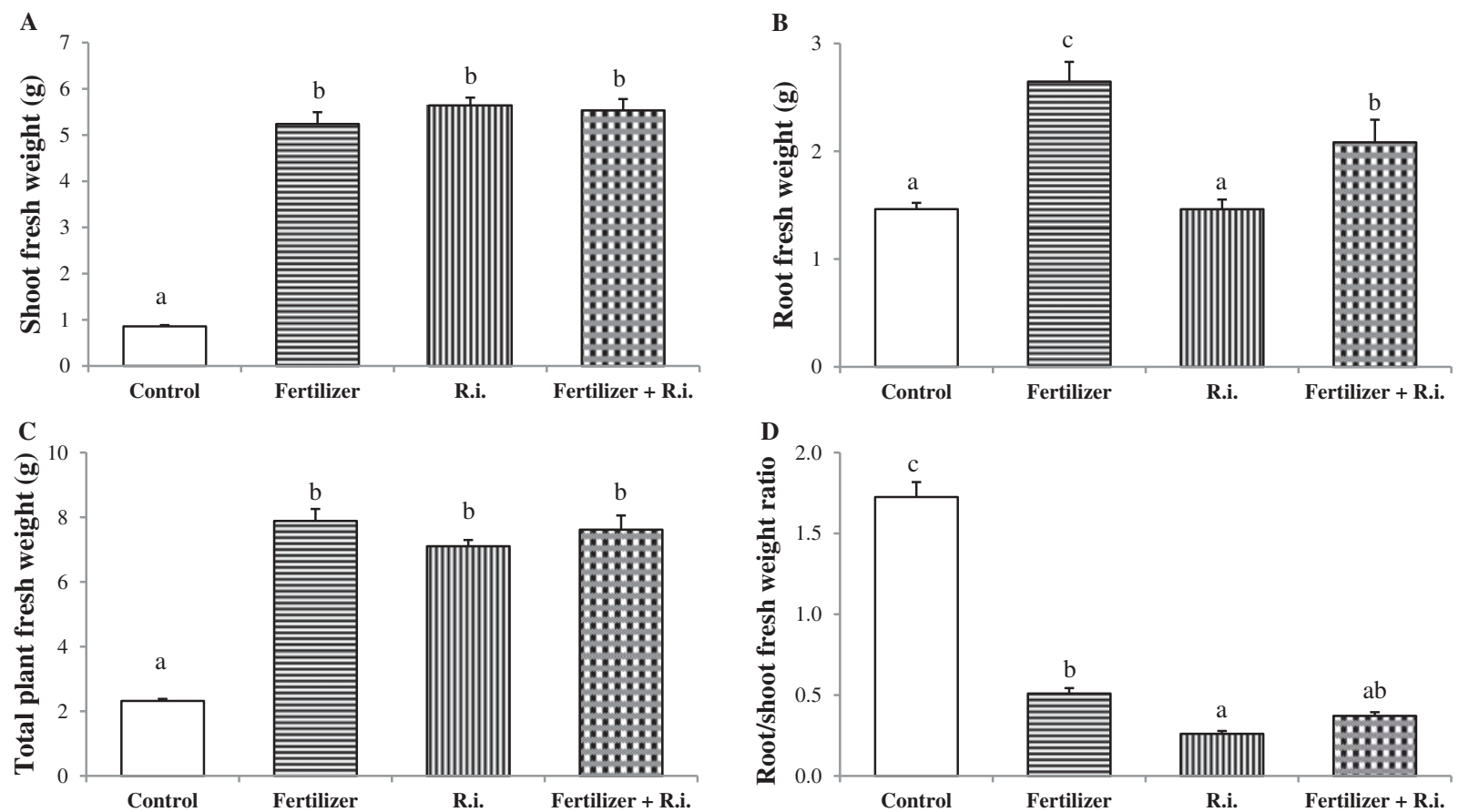

Figure 1. Shoot (A), root (B), and total plant (C) fresh weight and root/shoot fresh weight ratio (D) of Coriandrum sativum supplemented with chemical fertilizer and inoculated with Rhizophagus irregularis. Values are means $\pm 1 \mathrm{SE}$. Columns marked with the same letters are not significantly different according to Duncan's multiple range test at $p<.05$. R.i., Rhizophagus irregularis.

productivity in agroecosystems (Jeffries et al., 2003), their beneficial effects depend largely upon plant and fungal species involved in symbiosis (van der Heijden et al., 2015). Data demonstrated that $R$. irregularis improved the growth of $C$. sativum and therefore may be regarded as an alternative to application of PMNBS.

There was no marked improvement in shoot fresh weight and total fresh weight of plants simultaneously supplemented with chemical fertilizer and inoculated with $R$. irregularis compared with those only supplemented with PMNBS or only inoculated with $R$. irregularis. Evidence indicates that application of chemical fertilizer together with fungal inoculation does not enhance the growth of $C$. sativum. Therefore, inoculation with $R$. irregularis alone is preferred due not only to the observed effects on plant growth, but also to environmental benefits such that application of chemical fertilizer may be eliminated.

Plants supplemented with PMNBS displayed a significantly higher root fresh weight compared to any other treatment (Figure 1B). Inoculation with $R$. irregularis alone did not markedly influence root growth. However, plants simultaneously supplemented with chemical fertilizer and inoculated with $R$. irregularis showed a significantly higher root fresh weight compared with controls. Both fungal inoculation and application of chemical fertilizer markedly influenced root/shoot fresh weight ratio of C. sativum (Figure 1D). Plants from all mycorrhizal and fertilization treatments displayed a significantly lower root/shoot ratio than controls. The lowest root/shoot ratio was that of $C$. sativum inoculated with $R$. irregularis, showing that these plants had a significantly higher proportion of shoots. Smith et al. (2011) demonstrated that plants colonized by AM fungi possess lower root/shoot ratios. With the help of AM fungi, plants might take up soil nutrients more efficiently, and save energy and carbon for root production, concurrently increasing shoot growth in order to obtain higher photosynthetic rates (Maherali, 2014).

\section{Plant nutrition}

Inoculation with $R$. irregularis and application of chemical fertilizer significantly increased shoot $\mathrm{N}$ concentration of $C$. sativum compared with controls (Figure 2A). Plants inoculated with $R$. irregularis possessed the highest shoot $\mathrm{N}$ concentration, irrespective of the fertilization treatment. Plants 
supplemented with chemical fertilizer, plants inoculated with $R$. irregularis, and plants simultaneously supplemented with PMNBS and inoculated with the AM fungus showed significantly higher shoot $\mathrm{P}$ concentrations than controls (Figure 2B). Shoot P concentration was significantly higher in plants inoculated with $R$. irregularis than in plants supplemented with chemical fertilizer. Plants from all mycorrhizal and fertilization treatments displayed a significantly higher shoot $\mathrm{K}$ concentration than controls (Figure 2C). No marked differences in shoot $\mathrm{K}$ concentration were obtained among all mycorrhizal and fertilization treatments. Shoot concentrations of $\mathrm{N}, \mathrm{P}$, and $\mathrm{K}$ increased in plants inoculated with $R$. irregularis by 44,254 , and $27 \%$, respectively, compared with controls. The highest elevation was observed in shoot $\mathrm{P}$ concentration. Phosphorus is essential nutrient for plant growth; however, its low bioavailability in soils makes it difficult for plants to take up (Marschner, 2012). This limitation might be overcome by application of AM fungi. Improved P acquisition is one of the well-documented effects of

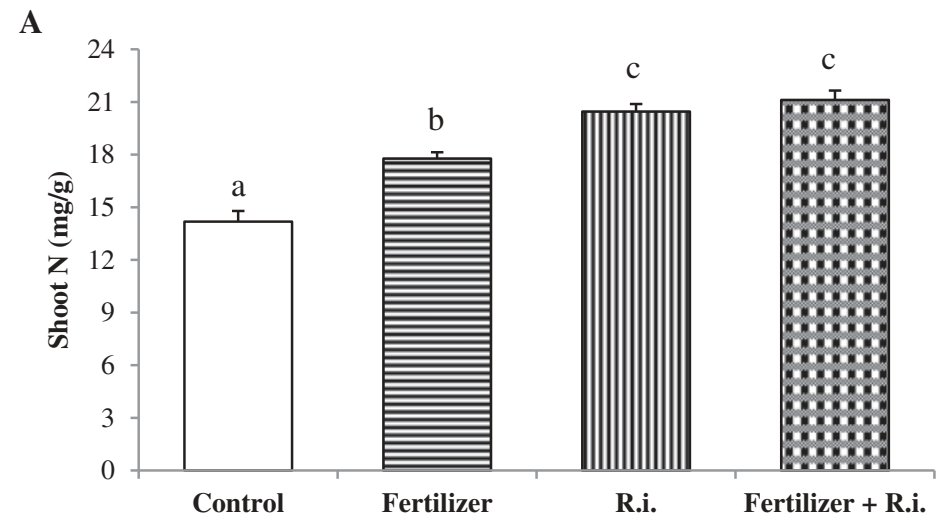

B
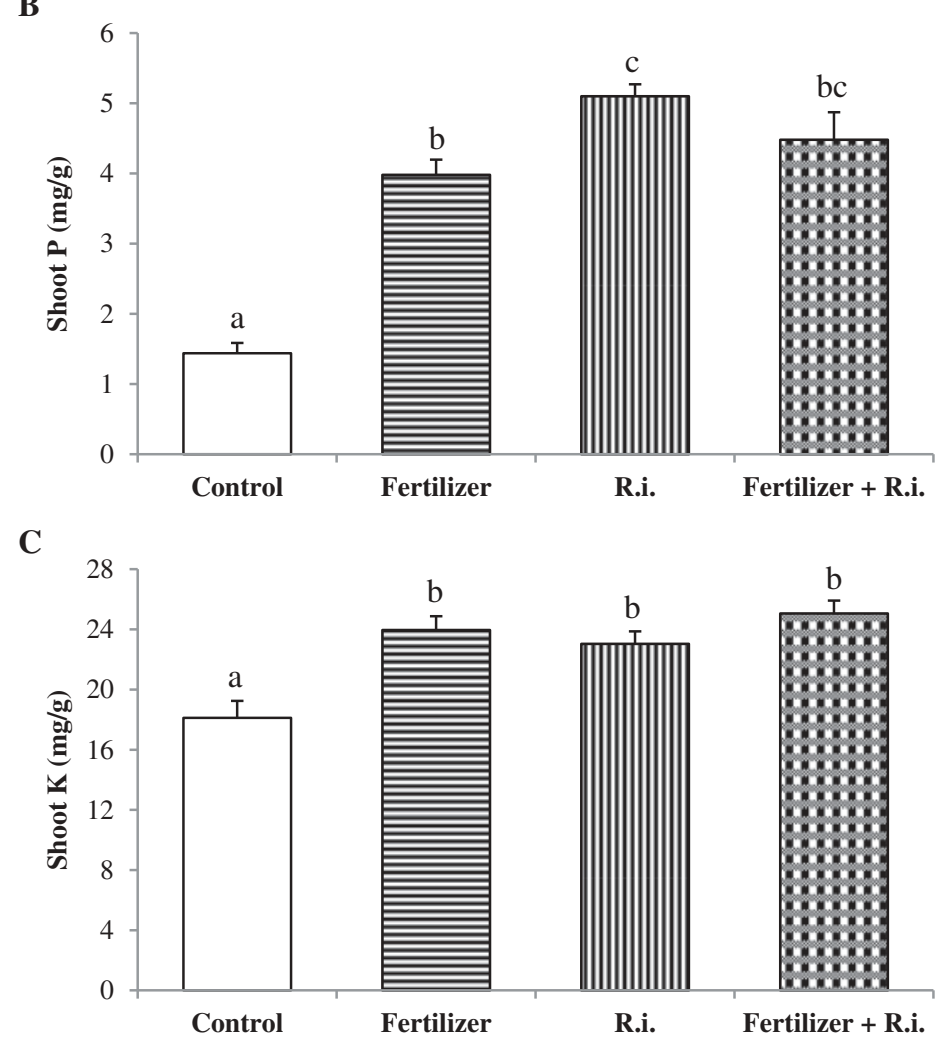

Figure 2. Shoot nitrogen (A), phosphorus (B), and potassium (C) concentration of Coriandrum sativum supplemented with chemical fertilizer and inoculated with Rhizophagus irregularis. Values are means $\pm 1 \mathrm{SE}$. Columns marked with the same letters are not significantly different according to Duncan's multiple range test at $p<.05$. R.i., Rhizophagus irregularis. 
AM fungi in plants (Oliveira et al., 2010; Smith et al., 2011). Increased tissue $\mathrm{N}$ and $\mathrm{K}$ concentrations are also common in mycorrhizal plants (Oliveira et al., 2005a; Willis et al., 2013). Data from the present study indicate that $R$. irregularis contributed to improve the nutritional status of $C$. sativum. This nutritional benefit may have also contributed to enhanced growth performance, which was observed in mycorrhizal C. sativum plants.

Leaf chlorophyll concentration was significantly higher in plants from all mycorrhizal and fertilization treatments compared with controls (Figure 3). Plants inoculated with $R$. irregularis demonstrated significantly higher leaf chlorophyll $\mathrm{a}$ and chlorophyll $\mathrm{a}+\mathrm{b}$ levels than plants supplemented with PMNBS (Figures 3A and 3C), while no marked difference in leaf chlorophyll $b$ concentrations was found between plants inoculated with $R$. irregularis and those supplemented with chemical fertilizer (Figure 3B). The concentration of chlorophyll is a physiological indicator of the photosynthetic potential of plants. AM fungi
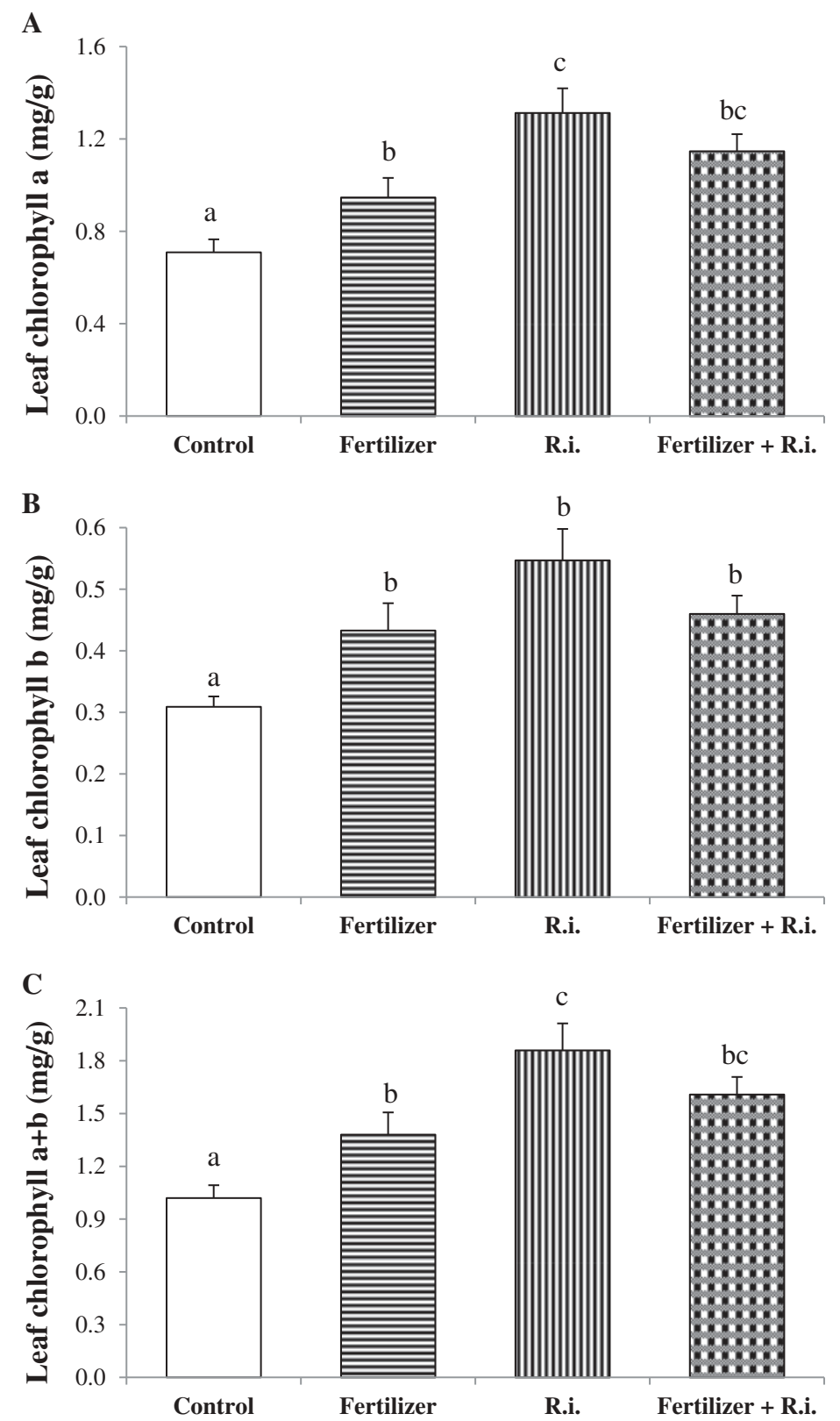

Figure 3. Leaf chlorophyll a (A), chlorophyll b (B), and chlorophyll $a+b(C)$ concentration of Coriandrum sativum supplemented with chemical fertilizer and inoculated with Rhizophagus irregularis. Values are means $\pm 1 \mathrm{SE}$. Columns marked with the same letters are not significantly different according to Duncan's multiple range test at $p<.05$. R.i., Rhizophagus irregularis. 
enhance the photosynthetic potential of their host plants by increasing the concentration of photosynthetic pigments (Oliveira et al., 2005a) and/or developing photosynthetically active tissue (Adolfsson et al., 2015). Vafadar et al. (2014) found significant elevation in chlorophyll a, b, and $\mathrm{a}+\mathrm{b}$ levels of the medicinal plant Stevia rebaudiana inoculated with $R$. irregularis. Inoculation with the same AM fungal species was also shown to increase leaf chlorophyll concentrations of other plant species (Oliveira et al., 2005a; Zhu et al., 2012). In the present study, inoculation with $R$. irregularis was equally or more efficient than application of PMNBS in enhancing the nutritional status and chlorophyll levels of C. sativum, indicating that AM fungi might serve as an effective alternative to chemical fertilizers.

\section{Effect of chemical fertilizer on fungal development}

There was no AM fungal colonization in the roots of noninoculated plants. Inoculation with $R$. irregularis resulted in 25 and 38\% RLC in plants with or without application of PMNBS, respectively (Table 1). These values are within the range of $11-43 \%$ reported by Schroeder and Janos (2004) for C. sativum. The percent RLC, arbuscule abundance, and ERM length were significantly reduced with application of chemical fertilizer. The increased availability of nutrients, especially $\mathrm{P}$, resulting from application of chemical fertilizers is known to inhibit AM development by reducing root colonization (Willis et al., 2013) and length of the ERM (Olsson et al., 2014). Data from the

Table 1. Mycorrhizal colonization and length of the extraradical mycelium of Rhizophagus irregularis with and without the application of chemical fertilizer.

\begin{tabular}{|c|c|c|c|}
\hline Treatment & $\begin{array}{c}\text { AMF } \\
\text { colonization } \\
\text { (\%RLC) }\end{array}$ & $\begin{array}{c}\text { Arbuscule } \\
\text { abundance (\%) }\end{array}$ & $\begin{array}{l}\text { ERM length } \\
\left(\mathrm{cm} / \mathrm{cm}^{2}\right)\end{array}$ \\
\hline $\begin{array}{c}\text { Rhizophagus } \\
\text { irregularis }\end{array}$ & $38 \pm 4$ & $45 \pm 4$ & $10 \pm 2$ \\
\hline $\begin{array}{l}\text { Fertilizer + } \\
\text { Rhizophagus } \\
\text { irregularis }\end{array}$ & $25 \pm 3$ & $20 \pm 5$ & $5 \pm 1$ \\
\hline $\begin{array}{l}\text { Student's } t \text {-test } \\
\text { significance }\end{array}$ & $*$ & $*$ & * \\
\hline
\end{tabular}

Note. Values are means $\pm 1 \mathrm{SE}$. Asterisk indicates significant effect at the level of $p<.05$. AMF, arbuscular mycorrhizal fungal; RLC, root length colonized; ERM, extraradical mycelium. present study showed that application of chemical fertilizer was detrimental to development of $R$. irregularis associated with C. sativum.

\section{Conclusions}

Coriandrum sativum inoculated with $R$. irregularis displayed higher shoot and total weight than noninoculated controls. This effect was probably due to enhanced uptake of soil nutrients mediated by AM fungus. Inoculated plants possessed also greater leaf chlorophyll concentrations, indicating enhanced photosynthetic potential. Mycorrhizal C. sativum plants showed improved growth and nutrition without input of chemical fertilizer. There were no significant differences in shoot and total weight between $C$. sativum inoculated with $R$. irregularis and those supplemented with PMNBS. Therefore, inoculation with AM fungi may be regarded as an alternative ecotechnological approach to application of chemical fertilizer in production of $C$. sativum. Further studies are required to determine the effects of AM fungi and chemical fertilizer on the essential oil content of C. sativum. AM fungi display potential to reduce dependence upon agrochemicals in agriculture, thus contributing to prevent environmental degradation and improve food quality, and consequently resulting in benefits to human health.

\section{Funding}

R. S. Oliveira and Y. Ma acknowledge the support of Fundação para a Ciência e a Tecnologia (FCT) through the research grants SFRH/BPD/85008/2012 and SFRH/BPD/ $76028 / 2011$ and Fundo Social Europeu (FSE). I. Rocha was supported by the FCT grant BI-EXPL/AGR-TEC/1204/2013. M. F. Carvalho acknowledges the Investigator FCT program supported by FCT, FSE, and Programa Operacional Potencial Humano (POPH). This work was financed by national funds through FCT under Project EXPL/AGR-TEC/1204/2013 and by Fundo Europeu de Desenvolvimento Regional (FEDER), Eixo I do Programa Operacional Fatores de Competitividade (POFC) of Quadro de Referência Estratégica Nacional (QREN) (COMPETE: FCOMP-01-0124-FEDER-041572). 


\section{References}

Adolfsson, L., Solymosi, K., Andersson, M. X., Keresztes, Á., Uddling, J., Schoefs, B., and Spetea, C. 2015. Mycorrhiza symbiosis increases the surface for sunlight capture in Medicago truncatula for better photosynthetic production. PLoS ONE 10: e0115314.

Alavanja, M. C. R., and Bonner, M. R. 2012. Occupational pesticide exposures and cancer risk: A review. J. Toxicol. Environ. Health B 15: 238-263.

Albrechtová, J., Látr, A., Nedorost, L., Pokluda, R., Posta, K., and Vosátka, M. 2012. Dual inoculation with mycorrhizal and saprotrophic fungi applicable in sustainable cultivation improves the yield and nutritive value of onion. Sci. World J. 2012: article 374091.

Augé, R. M., Toler, H. D., and Saxton, A. M. 2015. Arbuscular mycorrhizal symbiosis alters stomatal conductance of host plants more under drought than under amply watered conditions: A meta-analysis. Mycorrhiza 25: 13-24.

Baláz, M., and Vosátka, M. 2001. A novel inserted membrane technique for studies of mycorrhizal extraradical mycelium. Mycorrhiza 11: 291-296.

Baslam, M., Garmendia, I., and Goicoechea, N. 2013. Enhanced accumulation of vitamins, nutraceuticals and minerals in lettuces associated with arbuscular mycorrhizal fungi (AMF): A question of interest for both vegetables and humans. Agriculture 3: 188-209.

Brundrett, M., Melville, L., and Peterson, R. L. 1994. Practical methods in mycorrhizal research. Waterloo, ON, Canada: Mycologue Publications.

Carvalho, F. P. 2006. Agriculture, pesticides, food security and food safety. Environ. Sci. Policy 9: 685-692.

Freire, C., Koifman, R. J., and Koifman, S. 2015. Hematological and hepatic alterations in Brazilian population heavily exposed to organochlorine pesticides. $J$. Toxicol. Environ. Health A 78: 534-548.

European Commission. 2007. EU Policy for a sustainable use of pesticides: The story behind the strategy. Luxembourg: EC. http://ec.europa.eu/environment/archives/ppps/pdf/pesti cides_en.pdf

Giovannetti, M., and Mosse, B. 1980. An evaluation of techniques for measuring vesicular arbuscular mycorrhizal infection in roots. N. Phytol. 84: 489-500.

Jeffries, P., Gianinazzi, S., Perotto, S., Turnau, K., and Barea, J. M. 2003. The contribution of arbuscular mycorrhizal fungi in sustainable maintenance of plant health and soil fertility. Biol. Fertil. Soils 37: 1-16.

Koide, R. T., and Li, M. 1989. Appropriate controls for vesicular-arbuscular mycorrhiza research. N. Phytol. 111: 35-44.

Lim, W. M., Yong, J. L. S, and Suryadi, K. 2014. Consumers' perceived value and willingness to purchase organic food. J. Global Market. 27: 298-307.

Mahendra, P., and Bisht, S. 2011. Coriandrum sativum: A daily use spice with great medicinal effect. Pharmacognosy J. 3: 84-88.
Maherali, H. 2014. Is there an association between root architectu-re and mycorrhizal growth response? $N$. Phytol. 204: 192-200.

Maroufi, K., Farahani, H. A., and Darvishi, H. H. 2010. Importance of coriander (Coriandrum sativum L.) between the medicinal and aromatic plants. Adv. Environ. Biol. 4: 433-436.

Marschner, P. 2012. Marschner's mineral nutrition of higher plants, 3rd ed. London, UK: Academic Press.

Meyer, A., Koifman, S., Koifman, R. J., Moreira, J. C., Chrisman J. D. R., and Abreu-Villaça Y. 2010. Mood disorders hospitalizations, suicide attempts, and suicide mortality among agricultural workers and residents in an area with intensive use of pesticides in Brazil. J. Toxicol. Environ. Health A 73: 866-877.

Novozamsky, I., Houba, V. J. G., Van Eck, R., and Van Vark, W. 1983. A novel digestion technique for multi-element plant analysis. Commun. Soil Sci. Plant Anal. 14: 239-248.

Oliveira, R. S., Boyer, L. R., Carvalho, M. F., Jeffries, P., Vosátka, M., Castro, P. M. L., and Dodd, J. C. 2010. Genetic, phenotypic and functional variation within a Glomus geosporum isolate cultivated with or without the stress of a highly alkaline anthropogenic sediment. Appl. Soil Ecol. 45: 39-48.

Oliveira, R. S., Castro, P. M. L., Dodd, J. C., and Vosátka, M. 2005a. Synergistic effect of Glomus irregularis and Frankia spp. on the growth and stress recovery of Alnus glutinosa in an alkaline anthropogenic sediment. Chemosphere 60: 1462-1470.

Oliveira, R. S., Castro, P. M. L., Dodd, J. C., and Vosátka, M. 2006. Different native arbuscular mycorrhizal fungi influence the coexistence of two plant species in a highly alkaline anthropogenic sediment. Plant Soil 287: 209-221.

Oliveira, R. S., Dodd, J. C., and Castro, P. M. L. 2001. The mycorrhizal status of Phragmites australis in several polluted soils and sediments of an industrialised region of northern Portugal. Mycorrhiza 10: 241-247.

Oliveira, R. S, Vosátka, M., Dodd, J. C., and Castro, P. M. L. 2005b. Studies on the diversity of arbuscular mycorrhizal fungi and the efficacy of two native isolates in a highly alkaline anthropogenic sediment. Mycorrhiza 16: 23-31.

Olsson, O., Olsson, P. A., and Hammer, E. C. 2014. Phosphorus and carbon availability regulate structural composition and complexity of AM fungal mycelium. Mycorrhiza 24: 443-451.

Phillips, J. M., and Hayman, D. S. 1970. Improved procedures for clearing and staining parasitic and vesicular-arbuscular mycorrhizal fungi for rapid assessment of infection. Trans. Br. Mycol. Soc. 55: 158-161.

Power, A. G. 2010. Ecosystem services and agriculture: tradeoffs and synergies. Philos. Trans. R. Soc. B 365: 2959-2971.

Sahib, N. G., Anwar, F., Gilani, A. H., Hamid, A. A., Saari, N., and Alkharfy, K. M. 2012. Coriander (Coriandrum sativum L.): A potential source of high-value components for functional foods and nutraceuticals-A review. Phytother. Res. 27: $1439-1456$. 
Schroeder, M. S., and Janos, D. P. 2004. Phosphorus and intraspecific density alter plant responses to arbuscular mycorrhizas. Plant Soil 264: 335-348.

Sikes, B. A., Cottenie, K., and Klironomos, J. N. 2009. Plant and fungal identity determines pathogen protection of plant roots by arbuscular mycorrhizas. J. Ecol. 97: 1274-1280.

Skevas, T., Lansink, A. G. J. M. O., and Stefanou, S. E. 2013. Designing the emerging EU pesticide policy: A literature review. NJAS-Wagen. J. Life Sc. 64-65:95-103.

Smith, S. E, Jakobsen, I., Grønlund, M., and Smith, F. A. 2011. Roles of arbuscular mycorrhizas in plant phosphorus nutrition: Interactions between pathways of phosphorus uptake in arbuscular mycorrhizal roots have important implications for understanding and manipulating plant phosphorus acquisition. Plant Physiol. 156: 1050-1057.

Trouvelot, A., Kough, J. L., and Gianinazzi-Pearson, V. 1986. Mesure du taux de mycorhization VA d'un systeme radiculaire. Recherche de methodes d'estimation ayant une signification fonctionnelle. In Physiological and genetical aspects of mycorrhizae, ed. V. Gianinazzi-Pearson and S. Gianinazzi, 217-221. Paris, France: INRA Press.

Turra, C., Fernandes E. A. D. N., Stefanuto, V. A., Bacchi, M. A., Sarriés, G. A., and Reyes, A. E. L. 2010. Arsenic and chromium in Brazilian agricultural supplies. J. Toxicol. Environ. Health A 73: 910-915.

Vafadar, F., Amooaghaie, R., and Otroshy, M. 2014. Effects of plant-growth-promoting rhizobacteria and arbuscular mycorrhizal fungus on plant growth, stevioside, NPK, and chlorophyll content of Stevia rebaudiana. J. Plant Interact. 9: 128-136.

van der Heijden, M. G. A., Martin, F. M., Selosse, M.-A., and Sanders, I. R. 2015. Mycorrhizal ecology and evolution: The past, the present, and the future. N. Phytol. 205: 1406-1423.

Walinga, I., Van Vark, W., Houba, V. J. G., and van der Lee, J. J. 1989. Plant analysis procedures (Soil and plant analysis, Part 7). Wageningen, The Netherlands: Syllabus.

Wellburn, A. R. 1994. The spectral determination of chlorophylls a and b, as well as total carotenoids, using various solvents with spectrophotometers of different resolution. J. Plant Physiol. 144: 307-313.

Willis, A., Rodrigues, B. F., and Harris, P. J. C. 2013. The ecology of arbuscular mycorrhizal fungi. Crit. Rev. Plant Sci. 32: 1-20.

Zhu, X. C., Song, F. B., Liu, S. Q., Liu, T. D., and Zhou, X. 2012. Arbuscular mycorrhizae improves photosynthesis and water status of Zea mays L. under drought stress. Plant Soil Environ. 58: 186-191. 